\title{
Assessing the reality-Transport and land use planning to achieve sustainability
}

\author{
David Banister \\ University of Oxford
}

\section{Introduction}

Sustainability is tough, both in terms of how to define it and in terms of bringing it about in reality. Rather than becoming entangled in complicated definitions of the concept, it is better to set out a broad-based definition relevant to the transport domain, to explore how we can use substantially less rather than more carbon-based energy sources to provide the mobility needed for society to function efficiently. This means that transport must accept its responsibility to take at least a "fair" share of any targets set at the national (or international) level. In the past, transport has been the one major sector of the economy for which it has been difficult to make cuts in energy use and in carbon emissions.

This paper takes a historical perspective on how cities have become less sustainable in terms of transport, but it will argue that many positive changes have taken place even before the current concerns over $\mathrm{CO}_{2}$ and oil. There seem to be many more opportunities for further change through the encouragement of high-quality city-based lifestyles that do not require high levels of carbon-based mobility. But it is in the newly emerging "megacities" that the main problems occur, as there is a discontinuity between the slow growing, stable, and wellstructured cities of the west and the rapidly growing, unstable, and unstructured cities of the east.

The debates need to address the role of transport and land-use planning in these megacities that are growing at rates and on a scale that do not reside comfortably in the traditional planning framework. New visionaries are required to confront the problems of megacities, and innovative planning processes are necessary to facilitate rapid and adaptive change so that new urban structures can accommodate growth yet maintain flexibility. A hundred years of knowledge and experience about different forms of transport and urban structure needs to be concentrated into the next 10 years so that these megacities can emerge as the new models for transport and urban sustainability.

\section{The retrospective view}

\subsection{Changes in travel distance and modes of travel}

Before 1950, many cities had low levels of car ownership, and movement depended on walking, cycling, and public transport. These relatively slow forms of transport limited the growth of cities, but it must be realized that it was the introduction of public transport that permitted the initial expansion of cities from 1850 to 1950 . London provides a good example. In 1801, 87 percent of London's population was located in the inner area (20 percent of the total area- $1500 \mathrm{~km} 2)$, which amounted to 0.957 million out of a total population of 1.1 million. This was before the advent of public transport. By 1901,70 percent of the population (4.5 million out of 6.5 million) was still located in the inner area, even though decentralization had been facilitated by rail, tram, and bus. In 2001, 45 percent of the population (7.2 million) lived in the inner area, and in 2011, 40 percent of the population lived in the inner area and 60 percent in the outer area ( 80 percent of area). The car has only been influential in this process since the 1970s.

In his study of the London rail network development, Levinson (2008) found positive feedback between population density and network density over the period 1871-2001, where additional stations in the periphery on the underground and overground rail networks encouraged suburbanization and relocation, as land was cheap. In the center of London, more expensive land was increasingly being used for commercial development, the population moved out, and the concept of commuting was created ${ }^{1}$.

1 The word commute first took on a meaning of "traveling back and forth" about 100 years ago. But it wasn't the exchange of locations that gave commute this new meaning. In 1848 the American Railroad Journal reported that regular passengers traveling between Trenton and New Brunswick could buy a ticket good for eight train trips along that route. The special ticket was priced lower than eight individual tickets and was called a commutation ticket. This model was extended to mean "season ticket" for railway passages, and the use of commutation was consistent with other senses at the time of fees or taxes that where paid in lieu of some other means of payment. http:// podictionary.com/commute-podictionary-111/ 
By 1900, daily travel distances had increased to about 1 $\mathrm{km}$ per person per day, according to the Arnuld Grübler analysis in France, then rose to $10 \mathrm{~km}$ per person per day by 1960 and to $50 \mathrm{~km}$ per person per day by 2000 (Grübler 2004). The question here is, will this exponential increase in travel distance continue, or is the only logical conclusion that there are no limits to how far we can travel? The prognosis is not good when both distance and population are increasing. Andreas Schäfer et al.'s (2009) global analysis demonstrates the huge increases in passenger travel since 1950 and two contrasting views of future growth, driven by increases in population and wealth as well as by the continued globalization of the world economy and the maturity of the new network society (Table 1).

The numbers do not seem large, but the real scale of the increase is apparent. Mobility levels in the industrialized countries remain substantially higher than those elsewhere, with some convergence in the developing and reforming economies. But the real change is in the growth in the global population and in the distribution of that population, and this means that the total amount of travel distance will increase (2005-2050) 2.73 times (MIT-EPPA model) or by nearly four times (IPCC SRES-B1 Scenario). History suggests that travel distance is driven by income, education, and globalization, and that travel itself is becoming global as well as local. Thus, the limits to mobility have not yet been reached as both wealth and population are expected to continue to increase.

Table 1: Growth in global per capita travel distances.

\begin{tabular}{|c|c|c|c|c|c|}
\hline & 1950 & 2005 & 2050 & $1950-2005$ & $2005-2050$ \\
\hline & $\begin{array}{l}\text { PKT/ } \\
\text { cap }\end{array}$ & $\begin{array}{l}\text { PKT/ } \\
\text { cap }\end{array}$ & $\begin{array}{l}\text { PKT/ } \\
\text { cap }\end{array}$ & \% Change & $\%$ Change \\
\hline $\begin{array}{l}\text { Industrialized } \\
\text { economies }\end{array}$ & 4530 & 18400 & $\begin{array}{c}42200 \\
(29500)\end{array}$ & +306.2 & $\begin{array}{l}+129.3 \\
(+60.3)\end{array}$ \\
\hline $\begin{array}{l}\text { Reforming } \\
\text { economies }\end{array}$ & 947 & 5620 & $\begin{array}{c}15000 \\
(16300)\end{array}$ & +493.4 & $\begin{array}{l}+166.9 \\
(+190.0)\end{array}$ \\
\hline $\begin{array}{c}\text { Developing } \\
\text { economies }\end{array}$ & 388 & 3660 & $\begin{array}{c}6800 \\
(14600)\end{array}$ & +843.3 & $\begin{array}{c}+85.8 \\
(+298.9)\end{array}$ \\
\hline World & 1420 & 6020 & $\begin{array}{c}11400 \\
(16400)\end{array}$ & +323.9 & $\begin{array}{c}+89.4 \\
(+172.4)\end{array}$ \\
\hline
\end{tabular}

Source: Schäfer et al. (2009).

Units: Passenger kilometers traveled per person per year by all modes including air. Projections for 2050 are based on economic growth rates of the MIT EPPA model reference run and those of the IPCC SRES-B1 scenario (in brackets). Industrialized economies: North America, Pacific OECD, and Western Europe. Reforming economies: Eastern Europe and former Soviet Union.

\subsection{Planning history and the role of the visionaries}

In the past, the land-use planning system has had a major role in determining the urban structure in many cities, usually based in arguments that facilities and service should be accessible and that not all people have access to their own transport. There was also a desire among many planning visionaries to create high-quality liveable places for people that were spacious, safe, and secure. Planning also had a strong social role in that it provided the means for protecting the urban poor from rising land costs and speculation, thus making the city inclusive rather than exclusive. Since 1990, the most influential urban forms and interventions from planning visionaries have been focused on the following types of urban forms (based on UN Habitat 2009, p. 11; Hall and Tewdwr Jones 2010; and Banister 2005):

The Garden City, circa 1900 (UK): Small, self-contained satellite towns, detached dwellings, large plots of land, low densities, separation of incompatible land uses, radial road networks, and aesthetic, curving routes. The key individual was Ebenezer Howard (1850-1928) and his book Cities of Tomorrow (1902).

Greenbelts, circa 1935 (UK): Wide buffers of open space surrounding a town or city to prevent it from expanding outward and to separate it from new satellite towns (garden cities or new towns) beyond the belt. Originally proposed by the London County Council, but formalized by Sir Patrick Abercrombie in the Greater London Plan (1944).

The Neighborhood Unit, 1920s (US): Low-density expanses of open space focused on community facilities, minimizing conflict between cars and pedestrians by confining arterial routes to the periphery and discouraging through-traffic, based on the assumption that this layout will create social communities. The initial advocate was Clarence Perry (1872-1944).

Radburn Layout, 1928 (US): Closely related to garden cities, this layout is characterized by cul-de-sacs and super blocks free of traffic, where cars and pedestrians are separated from each other, and public facilities and shops are located on pedestrian networks and embedded in open space. Clarence Stein (1882-1975) developed these ideas in the USA.

Urban Renewal, 1930s onwards: "Slum" clearance and rehousing projects following Radburn or neighborhood unit layouts and urban modernism. The concept of reconstruction on the basis of precincts with a hierarchy of roads segregated from local streets originated with Sir Alker Tripp (1883-1954).

Road Hierarchies, 1960s (UK): Informed by the Buchanan Report (1963) on traffic in towns, this approach provides a rationale for urban traffic management and the problems of traffic congestion by creating a hierarchy of roads with different 
functions. At the lowest level of the hierarchy, an environmental cell (or residential area) carries only local traffic on "local distributors." At higher levels, district and primary distributors (freeways) carry passing and longer-distance traffic. The assumption is that every household will eventually own a car and all urban movement will be car based. These ideas fitted well with urban modernism and the two strands became closely interlinked.

New Towns, post-war UK: As a regional response to a perception of problems of growth in major cities (de-concentration), but also seen as a tool of development in lagging regions. The original idea came from Raymond Unwin (1863-1940) with Letchworth Garden City and from Barry Parker (18761947) with Hampstead Garden Suburb, but the more general New Towns movement was the work of Sir Frederick Osborne (1885-1978).

Through the 20th century, planners have had an instrumental role in determining what types of development should take place, trying to balance the market requirements as personified by the developer with the social necessity of ensuring good-quality residential accommodation and accessibility to services and facilities. This core activity of many city planners was supplemented by a continuous rethinking of urban form, with major new ideas being promoted by the planning visionaries (some of whom are noted above) together with their individual contributions.

Although there were many similarities between the visionaries identified here, there was also one clear set of differences between thinking in the USA and Europe.

Suburbia: From the 1920s onward in the USA, undefined and extensive areas of residential development were constructed on the urban periphery-with single-family units, low densities, and large plots of land — structured around car movement systems, serviced with community facilities and shopping malls, and demonstrating high levels of car ownership, access, and affluence. In the 1930s, Frank Lloyd Wright (1869-1959) argued for the dispersion of both homes and jobs in the USA through the concept of Broadacre City," where homes would be surrounded by an acre of land (enough to grow crops on), and car accessibility would be provided by roads.

Urban Modernism: New urban developments in Europe were seen to be much higher density, following the ideas of Le Corbusier (1887-1965), where tower-blocks "floated" in open space, connected by car-accessible parkways (La Ville Radieuse); or the linear pattern of city development promoted by Arturo Soria y Mata (1844-1920), with a central rapid transit system (La Ciudad Lineal).

In addition to these key thinkers, there was a second group of visionaries that looked at city development in the wider re- gional context rather than planning as civic design. To some extent Howard had anticipated this change, but it was Patrick Geddes (1854-1932) who examined cities in evolution and the growth of conurbations (he first used this term) and suburban decentralisation (Geddes 1915), and his ideas were taken up in the USA by Lewis Mumford (Mumford 1938). This grand scale of thinking reached its apogee with Sir Patrick Abercrombie's (1879-1957) Greater London Plan (1944) that brought together the ideas of many of the individuals mentioned here into one blueprint for the development of the London region (2500 km2), with 10 million people. His main idea was to move 10 percent of the population out of the central city into new planned communities of medium density that were self contained, so that both jobs and housing were provided. This was suburbanization on a grand scale, but planned rather than left to the market, as in Wright's Broadacre City.

Perhaps the most influential book is celebrating its 50th anniversary (Jacobs 1961),because its underlying arguments have really stood the test of time and because they came out of community action against the wholesale reconstruction of cities. In this case, it was Robert Moses building highways through central New York and in Jane Jacob's own backyard (Greenwich Village). Jacob's argument was that community could not be created but only destroyed, and that urban renewal must come from mixed use and the vitality of existing neighborhoods, designed around local movement, small scale shops and businesses, and open space. She was criticized for overemphasizing the importance of urban form in shaping local communities and in promoting the interests of the working class in renewal rather than in redevelopment. With hindsight, it seems that the main beneficiaries were the middle class, with the subsequent gentrification of these areas (Glaeser 2011). But her main arguments about the importance of social capital are fully supported, as relatively dense and lively neighborhoods encourage mixed communities (all ages, ethnicities, and classes) with lower levels of crime, and they foster innovation, creativity, and employment. Perhaps the role of the planning visionaries is not to create new idealized forms of urban development, but to create the conditions that preserve and enhance the quality of inclusive and adaptable neighborhoods for people.

\subsection{The compact city approach}

In all of this debate, issues relating to the environment were not considered important, and urban quality was seen as the outcome of "good planning." It was only in the early 1970s, with the publication of the Limits of Growth (Meadows et al. 1972), that environmental quality became a major political concern. 
Even then, the concern was mainly over the local environmental quality, including some pollutants, air quality, noise, and community severance, but not issues relating to carbon or the future of oil. The oil crisis of 1973 was quickly forgotten, and oil's low cost and abundance continued to dominate the debate at the expense of concerns over security of supply, resource depletion, and carbon.

It has only been in the last 20 years, since the World Summit in Rio (1992) and the climate agreement in Kyoto (1997), that global warming has become a major concern of science and policy. It took more than seven years for the Kyoto Protocol to be ratified (February 2005). Since that time, there has been frenetic activity in examining how sustainability can be placed at the center of transport in urban areas, so that the twin axes of development (economic and social) can be balanced against the new third axis (environmental). These three "pillars of sustainability" have been at the heart of the debates on future urban form.

Since the 1990s, the EU has promoted the "compact city" approach that argues for medium (and high) residential densities, enabling efficient public transport and thresholds to support concentrations of economic activity, services, and facilities (CEC 1992). Mixed-use environments and good public open spaces are important, with urban containment policies implemented through the demarcation of a growth boundary or urban edge. Compaction or higher building densities help cut the volume of traffic in urban areas, and this was seen by the EU as the main means to provide cities with environmental and quality-of-life benefits.

This rather simplistic view of development failed to recognize the complexity of choices about travel, as the location of facilities near housing does not mean they will be used. But equally, it does not negate these arguments, as there may be strong accessibility reasons for co-location of services/facilities and homes (Breheny 1992). Similarly, economic issues such as incomes and fuel prices are normally considered to be much stronger influences on travel patterns than urban form. Planning decisions are seen as difficult and expensive ways to influence travel behavior, and market pressures for decentralization out of cities are always likely to be stronger influences on city development. It seems in retrospect that the optimism of the EU may have been misplaced, as the strength of the supposed impacts of land use on transport has been questioned (Breheny and Archer 1998). Equally, much of the increase in travel is a result of decisions taken in other sectors, as the location of new housing and retail centers generate new transport pressures.

The current thinking in the EU is for smart, sustainable, and inclusive growth (EU 2010), but compact city planning is still central to reducing the intensity of individual car use and for developing higher quality public transport connectivity between the city and its functional urban agglomeration. Progress will evolve around integration within the planning process and across sectors, and through multi-level governance across the city and the wider agglomeration. The increased concern over process rather than just the physical dimensions of compactness seems an important step in facilitating change (Neuman 2005).

\subsection{New urbanism}

The compact city debate has moved from the city to the agglomeration and a concern over governance, but the new urbanism approach reflects this through the examination of some of the same principles at the local neighborhood scale. Local neighborhoods are seen as composed of "fine-grained, mixed-use, mixed housing types, compact form, an attractive public realm, pedestrian-friendly streetscapes, defined centres and edges, and varying transport options" (Grant 2006, p.8). This means that a wide range of facilities are grouped together around key public transport facilities and intersections to maximize accessibility by efficient forms of transport (e.g., walking and cycling as well as public transport), but there is a concern that these types of development are not diverse or dynamic as they are only attractive to certain types of people.

Within the context of transport, the new urbanism is linked to transit-oriented developments (TOD), where higher densities and better public transport access are traded off against the greater flexibility of the car. In some situations TODs can reduce car use per capita among their residents by half and save households around 20 percent of their income, as they have lower levels of car ownership (Cervero 2008). An extensive review paper in the US (Ewing et al.. 2007), concluded that some 85 million tons of $\mathrm{CO} 2$ could be saved annually (in 2030) by shifting 60 percent of new growth to compact developments. The new urbanism and TODs both reduce the ecological footprint in cities, as it is easier to use the full range of planning possibilities outlined earlier to constrain the spatial spread of cities.

The new urbanism debate encourages more local activity through more walking, direct routing for slow modes of transport, and quieter and narrower streets (Duany and PlaterZyberk 1992; Calthorpe 1993). People travel shorter distances when they move into neighborhoods with higher accessibility (Krizek 2003), with median distance increasing from $3.2 \mathrm{~km}$ in the more accessible neighborhoods to $8.1 \mathrm{~km}$ in less accessible neighborhoods. Street connectivity is also important here, as it can reduce distances for slow modes; however, cul de sacs are also popular with residents even though they tend to ex- 
tend travel distances. "Main Street" programs in the US (and more recently, in the UK) are intended to revitalize town centers by restricting access at certain times and to create vibrant communities day and night (Handy 2004). Other initiatives to encourage urban living include extensive pedestrianization, the closure of residential streets, gated communities, and even the removal of freeways (e.g., the Embarcadero Freeway in San Francisco).

One of the few detailed empirical studies has been carried out in Toronto (Norman et al. 2006) for city center apartments (net residential density: 150 dwellings/hectare) and suburban detached housing (net residential density: 19 dwellings/hectare). Although the GHG emissions and energy density were similar per unit of living space $\left(\mathrm{m}^{2}\right)$ for construction materials, building operations, and transport, the figures per person are very different (Table 2). This is due to the additional space available per person in the suburban detached housing. The GHG emissions are 2.5 times higher in the suburban than the urban housing. For transport, the figures are stark, with GHG emissions (and energy use) more than 3.5 times greater in the low-density housing for car and 6.5 times greater for public transport.

Table 2: GHG emissions for different housing types in Toronto.

\begin{tabular}{clrrr}
\hline $\begin{array}{c}\text { Annual GHG Emissions - } \\
\mathrm{kg} \mathrm{CO} \text { e/person/year in 1996 }\end{array}$ & $\begin{array}{l}\text { Suburban } \\
\text { Detached }\end{array}$ & \multicolumn{3}{c}{$\begin{array}{c}\text { Urban } \\
\text { Apartments }\end{array}$} \\
\hline Construction & 5977 & & 391 & 12 \\
Building operations & 2730 & 32 & 1510 & 45 \\
Car travel & 5180 & 60 & 1420 & 43 \\
Bus transport & 1301 & & 20 & - \\
\hline
\end{tabular}

Based on Table 4 in Norman et al. (2006).

\subsection{Urban form and density}

Much of the discussion about the relationships between urban form and transport have concentrated on density as the instrumental variable, mainly for sound reasons that a certain logic links higher densities, shorter distances, and greater use of public transport, walking, and cycling. This logic has become more important in the recent extension of the debate from the economic and social elements of the city to the environmental aspects, as these now include energy use and carbon reduction. The physical attributes are strengthened by the need to also consider the environmental costs of different urban forms.

More recently, concepts of integration and complete journeys have also become more important, as it is not just one element of the journey that is important, but the door-to-door experience of travel, often by a combination of modes of transport (Givoni and Banister 2010). It is here that TODs have been extended to cover transport development areas (TDAs), where accessible public transport is part of development, so that a range of activities (e.g., offices, shops, social and recreational facilities) can all be accessed at the transport interchange. This means that development is concentrated at the interchange through construction above or immediately adjacent to it, so that users can walk to their destinations. Public transport interchanges with associated high-density complementary activities become the new nodal points for activity, and this also generates the possibility of these nodes becoming places to meet and spend time and money, rather than spaces to just pass through as quickly as possible.

Land use effects on travel behavior tend to be cumulative and mutually reinforcing (Hickman 2007; Litman 2007). This effect can be illustrated in two ways. Ewing and Cervero (2002) calculated the elasticity of vehicle trips and travel per capita with respect to four land use variables (Table 3). Their estimates suggest that a doubling of local density reduces car trips by 5 percent per capita and travel by about the same amount. Although the elasticities are low, Ewing and Cervero (2002) concluded that the land use effects were cumulative, thus giving the potential for 13 percent and 33 percent decreases in trips and trip distance, respectively.

Table 3: Elasticities of trips and travel by land use factors.

\begin{tabular}{clcc}
\hline Factor & \multicolumn{1}{c}{ Description } & Trips & $\begin{array}{c}\text { Travel } \\
\text { (VMT) }\end{array}$ \\
\hline Local density & $\begin{array}{l}\text { Residents and employees divided } \\
\text { by land area }\end{array}$ & -0.05 & -0.05 \\
\hline Local diversity & Jobs/residential population & -0.03 & -0.05 \\
\hline Local design & $\begin{array}{l}\text { Sidewalk completeness/route } \\
\text { directness and street network } \\
\text { density }\end{array}$ & -0.05 & -0.03 \\
Regional & $\begin{array}{l}\text { Distance to other activity centers } \\
\text { in the region }\end{array}$ & - & -0.20 \\
accessibility & & \\
\hline
\end{tabular}

Note: VMT = Vehicle miles traveled.

Source: Ewing and Cervero (2002).

The more recent literature again reflects this uncertainty. The meta-analysis carried out by Ewing and Cervero (2010) built on their earlier work (2002) and came to similar conclusions, namely, that VMT is most strongly related to accessibility at destinations, and then to street network layout and design. For walking, the land diversity, intersection density, and number of destinations within walking distance all featured as significant factors. For bus and rail, proximity to transit and street network design were important. Job and population densities did not feature as major factors, but this finding was at odds with the New York study by Chen et al. (2008), which linked car ownership with propensity to drive, and here employment density featured strongly as a significant determinant of mode 
A brief historical perspective on the density debate

\begin{tabular}{|c|c|c|c|c|c|c|c|}
\hline \multicolumn{8}{|c|}{$\begin{array}{l}\text { Typical US residential densities ar } \\
\text { per acre ( } 240-480 \text { per hectare). }\end{array}$} \\
\hline \multicolumn{8}{|c|}{$\begin{array}{l}\text { In the UK, the Georgians built to high densities of 100-200 dwellings per hectare (London, Edinburgh, and Bath) and the Victorians to lower densities } \\
\text { of } 40-80 \text { dwellings per hectare; current averages are about } 23 \text { dwellings per hectare. }\end{array}$} \\
\hline \multicolumn{8}{|c|}{$\begin{array}{l}\text { The Tudor Walters Report (1918) recommended } 30 \text { dwellings per hectare, the Howard's Garden City (1902) about } 45 \text { dwellings per hectare, and the } \\
\text { Friends of the Earth's Sustainable Urban Density is } 69 \text { dwellings per hectare (1999). }\end{array}$} \\
\hline \multirow{2}{*}{\multicolumn{8}{|c|}{$\begin{array}{l}\text { UK government directives are designed to build to higher densities in urban areas_-around 35-40 dwellings per hectare, and } 50 \text { dwellings per hectare } \\
\text { are being sought in some locations_-but nowhere as high as those of } 100 \text { years ago. } \\
\text { Note that much of the potential savings from building at higher densities are obtained from increasing density from low levels to medium levels_-75 } \\
\text { percent of the land savings are obtained by net densities of } 40 \text { dwellings per hectare, or gross densities (with facilities, etc.) of } 50 \text { dwellings per hectare. There } \\
\text { is a need to avoid very low densities (<20 dwellings per hectare) and to target in the range of } 40-50 \mathrm{dwellings} \mathrm{per} \mathrm{hectare} \mathrm{(Banister} \mathrm{2007).} \\
\text { Wachs (2002) suggests that doubling urban residential density would lead to a reduction of about } 15 \text { percent in trips but an increase in trip density, so } \\
\text { total travel increases. He also states that the US "spends more public money on transit per rider served than any country in the world" (p. 24). } \\
\text { Some cities have much higher densities, while others' are very low. For example, dwellings per hectare for Beijing is } 146 \text {; Tokyo, 130; New York City, } 90 \text {; } \\
\text { Los Angeles, } 40 \text {; and Dallas, } 2 \text {. }\end{array}$}} \\
\hline & & & & & & & \\
\hline \multirow{2}{*}{$\begin{array}{l}\text { Density } \\
\text { dwellings } \\
\text { perhectare }\end{array}$} & \multicolumn{3}{|c|}{ Net } & \multicolumn{4}{|c|}{ Area required with local facilities } \\
\hline & Land needed & Land saved & \%Total saving & Land needed & Land saved & \%Total saving & $\%$ cumulative \\
\hline 10 & 40.0 & & & 46.3 & & & \\
\hline 20 & 20.0 & 20.0 & 50.0 & 45.4 & 25.3 & 21.0 & 45.4 \\
\hline 30 & 13.3 & 6.7 & 16.7 & 61.3 & 17.9 & 7.4 & 15.9 \\
\hline 40 & 10.0 & 3.3 & 8.3 & 69.1 & 14.3 & 3.6 & 7.8 \\
\hline 50 & 8.0 & 2.0 & 5.0 & 73.9 & 12.1 & 2.2 & 4.8 \\
\hline 60 & 6.6 & 1.4 & 3.5 & 77.1 & 10.6 & 1.5 & 3.2 \\
\hline
\end{tabular}

"Density has little to do with overcrowding or town cramming. It has everything to do with design of the environment—the balance of massing, light, and space. By controlling the way buildings are arranged around public spaces, by ensuring that privacy is guaranteed and noise levels contained, it is possible to create attractive living environments, and to develop stronger and more vibrant communities," Rogers and Burdett (2001, p 12).

The US literature is also variable in its findings. Ewing (1997) estimated that a doubling of density resulted in a 25-30 percent lower level of vehicle miles travelled (VMT), while Holtzclaw (1994) concluded that the difference between 50 dwellings/hectare (urban densities) and 12.5 dwellings/hectare (suburban densities) was a 40 percent increase in travel. Overall, the US evidence seems empirically powerful, suggesting that higher density developments can reduce VMT by at least 10-20 percent as compared with urban sprawl (Litman 2007).

Sources: Haughton and Hunter 1994: Wachs 2002; Hall 2001; DETR 1998; and Rogers and Burdett 2001.

use. The jury is out and there is still no consensus.

\section{Urban planning for sustainable urban development}

\subsection{The bigger picture}

Throughout this retrospective view on the arguments over the roles and relationships between transport, land use, and planning, two themes have emerged. One is that people are and should be at the center of the debate, not arbitrary standards about levels of density and very physical interpretations of land use and planning. Related to this is the need to consider urbanity, where the function of urban living is to increase the means by which people can interact with each other and feel a sense of belonging through engagement with the full range of urban organizations and institutions. Second, the more recent debate on the importance of the environment has given a new impetus to the need for higher-density forms of living, as the global population increases and as the proportion living in urban areas increases from 50 percent (2008) to 70 percent (2050). Cities must be where most people live, as they make the most efficient use of available land and allow for the greatest economies of scale and scope; people should also live where they are less dependent on non-renewable resources.

These arguments are reinforced by the recent UN habitat reports Planning Sustainable Cities (2009) and Cities and Climate Change (2011), and the forthcoming report Sustain- 
able Urban Mobility (2013). In the 2009 Report (UN Habitat 2009, p. 129), eight sustainability directions were identified so that cities can address sustainable urban development in an integrated way. The energy themes cover the use of renewable energy, carbon neutral investments that improve energy efficiency, and distributed local electricity and water systems. Three other themes reflect the need for cities to move toward more local production (biofuels, food and fibres, and biodiversity), eco-efficient strategies for industry (to include waste and recycling), and the means to improve the housing stock. The two final themes are most relevant here, as they reflect the importance of place strategies and transport.

The "sense of place" strategies promote the human dimension, driving all the other strategies. This can be assisted by local economic development strategies, by place-based engagement approaches to all planning and development processes, and by the innovative use of "sustainability credits," or complementary currencies, to implement local sustainability innovations as development bonuses. The sustainable transport strategies include high-quality, fast transit along each main corridor, dense TODs built around each station, pedestrian and bicycle strategies for each center and TOD (with cycle links across the city), plug-in infrastructure for electric vehicles as they emerge, cycling and pedestrian infrastructure as an integrated part of all street planning, and a green wall growth boundary around the city to prevent further urban encroachment.

The report (UN Habitat 2009, p. 219) concludes that "there is some agreement that an equitable and sustainable city will have the following spatial features: higher densities but low rise; mixed uses; public transport based; spatial integration; a defined and protected open space system; and an urban edge to prevent sprawl." There is an awareness that this ideal may be far easier to achieve in developed countries, where there is much greater institutional capacity to bring about compliance with the supporting organizations, processes, and enforcement necessary to carry out the intentions. But the report is optimistic in that it still considers achieving these principles in different contexts a worthwhile goal.

In the rapidly growing cities of the developing world, these changes are much harder to bring about, as the issues raised are much more fundamental than promoting good practice in sustainable transport. For example, informal developments at the urban edge may negatively affect the poor by raising urban land values and by removing the possibility of settlement in locations beyond the edge. Figure 1 shows the growth in population of four world cities, illustrating the recent surge in the populations of Beijing and Shanghai since about 1960, with each of their populations more than doubling from high base populations of 7.3 million and 10.5 million, respectively (1960). Even at that time, they were larger than London was in 2000 or New York was in 1990. Looking back over time, it can be seen that London has followed a steady path of population increase, reaching 1 million in 1805,5 million in 1885, and a peak of 8.6 million in 1940. New York's population growth pattern is similar to that now being experienced in China, as it was also subject to mass inward migration. The population in

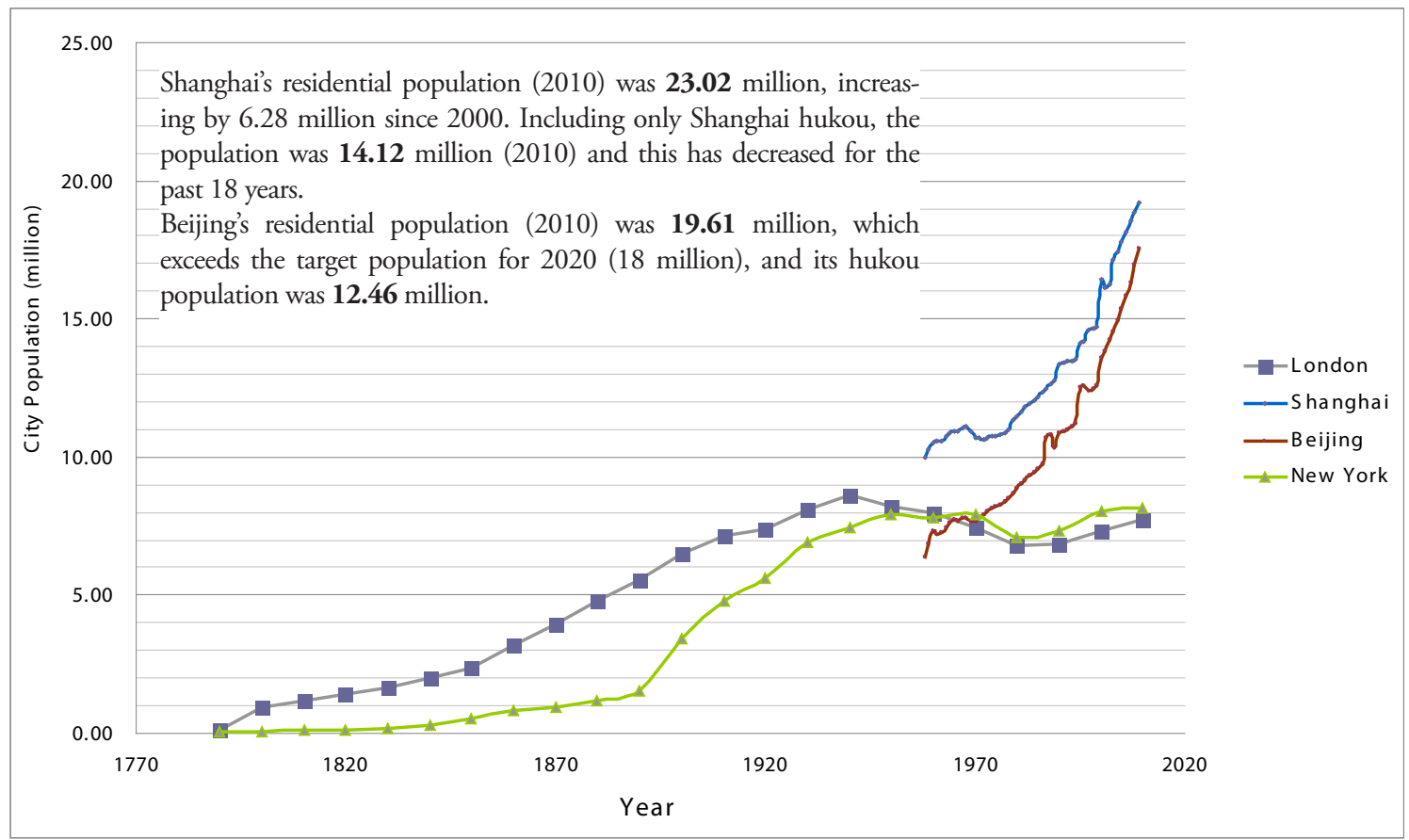

Figure 1: Population growth in London, New York, Beijing, and Shanghai. 
New York reached 1 million in 1875, but from 1890 to 1940 it rose from 1.5 million to 7.5 million - a fivefold increase over a 50 -year period. The patterns of population growth and migration in the Chinese cities are not new, even though the speed and scale of change may be substantially larger.

\subsection{Cities in developed countries}

Much of the evidence from the developed countries is well known, even if the evidence is slightly different (between Europe and the USA). The history has been used to explain the development of the arguments for certain types of urban form that may reduce transport-based energy use in cities. Even here progress has proved difficult, as there has been a continuous growth in the demand for travel. In these cities, there are strong institutional and governance structures that allow development to take place in a systematic and ordered way, with well-established decision-making processes, strong public-sector involvement, and consistent funding streams.

Over the last century, cities have spread with the creation of suburbia, even though populations have remained stable or declined. But more recently there has been a refocusing on concentration with extensive redevelopment of brownfield sites. People have moved back into the city, and with the growth in labor mobility, migration has also increased the city populations. As trade and labor barriers have been reduced, many young people have flocked to the cities, bringing new skills and cultures.

In transport terms, this has meant greater demand, but in many situations walking, cycling, and public transport have accommodated this increase, with over half of all trips in the city now being made by walking and cycling, and a further 20-30 percent by public transport. As a result of people returning to the city, densities have increased and through choice (and necessity) a higher priority has been given to the slower modes of transport. This in turn has led to more sustainable transport systems, as the growth in car-based travel has been stemmed in the city center and even in the suburbs. Such a change has been facilitated by policy and planning interventions, but the main driving force has been the new forms of mobility demanded by the new city dwellers. Many of these have not owned a car, and there seems to be some evidence that young people are moving away from car-dependent lifestyles (Stokes 2011). Effective policy measures allow such changes to take place by providing suitable homes, workplaces, and transport systems, and they reinforce changes that are already taking place by providing complementary support to reduce travel distances and the need to travel.

Such an argument is promoting an explicitly social di- mension to the more central thinking behind the new economic geography (Krugman 1991), where increasing returns to scale promote concentration of activity, and where transport costs are seen to be important in determining market structure. Central to the case is factor mobility, where knowledge, information, and labor are instrumental in determining the spatial pattern of development (Krugman 2011). The desire for urban living and the opportunities that it offers are central to the attraction of the city, as well as the sound economic reasons for clustering and concentration. To some extent this reasoning also counters Storper's concerns about the need to include knowledge and information spillovers and other intangibles to fully explain the complexity of the processes taking place (2011; the dormitive properties of new economic geography).

These changes have taken place over the last 100 years against a background of stable decision making, limited migration, and strong organizations, with some visionary inputs. Within Europe such an approach has had considerable success, as many cities (large and small) have created high-quality urban environments that provide the range of opportunities needed by the residents, and the transport system has developed in a supporting way that is sustainable. Perhaps even in these situations the changes were taking place before the carbon imperative had been fully realized (1990s), and this has strengthened the resolve of city (and national) governments. Concerns over congestion, safety, local pollution, and community were already shaping the agenda, and it had long been recognized that transport had to adapt to the city.

Even in the USA and Canada, similar arguments were being made, but the solutions were much less clear and the opportunities for more local travel and public transport more limited. Here the priority has been given to improving the efficiency of the car rather than redesigning the city, but where opportunities for more concentrated development have arisen, they have been taken. Land-use planning can operate effectively under these conditions, even though real change seems to take a long time to come to fruition. There is a strong need for flexibility in the process so that the transport system is responsive to external changes (Ingersoll 2006).

\subsection{New perspectives on transport and land use plan- ning-the China syndrome}

The recent growth in cities in the developed countries has been dramatic, but it is very modest when compared with the unbelievable change that is taking place elsewhere in the world. A completely new agenda is required to address the formidable expansion of the megacities (population over 10 million), and the growth of the megacity region (population over 20 mil- 
lion). Planning is an evolutionary process, and it is difficult for it to provide a stable environment for a revolutionary process. The rate of change taking place in terms of the urbanization process, and the scale of that change, is hard to comprehend, as cities are growing at annual rates of over 5 percent.

China demonstrates all of these characteristics with massive internal migration from the periphery (Central and West China) to the core (East and Coastal China), with a focus on manufacturing in the South East (Shanghai and the Pearl River Delta) and in the North (Beijing and Tianjin). Although this migration is driven by the expectations of employment and better-paid work, the new dimensions to the urban debate are the speed and scale of urbanization that is taking place (Table 4). Both these factors are unprecedented in history, and established thinking and theories cannot accommodate them. In 1990, 254 million people in China lived in urban areas (20 percent), but by 2005 this figure had risen to 572 million (44 percent), with a third of the population increase resulting from migration. By 2025, the total number of people living in Chinese urban areas will be 926 million (64 percent of the total population), and the expected migration (2005-2025) will be 243 million-69 percent of all growth. (McKinsey 2009).

Many young people are moving to the cities, despite the Chinese residence registration scheme that reduces the status and rights of migrants (Hukou system ${ }^{2}$ ). There are currently 145 million migrant workers in China (11 percent of the total population), and there are 225 million rural-born migrant workers (20 percent) working in urban areas. If this system were to change, then the movement to the urban areas might well accelerate, as urban income levels are more than three times as much as rural incomes (US \$758 in 2010). Much of the development is being funded by the sale of land, as this provides nearly half of all local government revenues, so the next development is being funded by the last one. By 2025 there will be 221 cities in China with a population of more than 1 million (as compared with 35 cities in Europe); 15 of these will have a population between 5 and 10 million, and

2 A hukou refers to the system of residency permits which dates back to ancient China, A household registration record officially identifies a person as a resident of an area and includes information such as name, parents, spouse, and date of birth. In 1958, the Chinese government officially promulgated the hukou system to control the movement of people between urban and rural areas to ensure some structural stability. After the Chinese economic reforms in late 1970s, it became possible for some to unofficially migrate and get a job without a valid permit. The system underwent further relaxation in the mid-1990s and then in the early 2000s. Rural residents can buy a temporary urban residency permit to work legally. By 2004, the Chinese Ministry of Agriculture estimated that more than 100 million people registered as "rural" were working in cities. However, these reforms have not fundamentally changed the hukou system. Instead, reforms have only decentralized hukou control to local governments. It has been argued that the system will have to be further relaxed to increase the availability of skilled workers to industries. there will be 8 megacities (population greater than 10 million).

A strong economic rationale lies behind this urbanization process. It is consistent with resource availability and exportled manufacturing, providing an extreme example of Krugman's core-periphery model (1991), with industrial clustering and localization, together with specialization. In addition the larger cities have attracted the best-educated workers and more international investment; there also seems to be network benefits arising from better communications and transport infrastructure.

The key question presented here is the choice that now confronts China in terms of the most appropriate pattern of urban development that can be considered sustainable, and what transport system is best suited to such a structure. Over and above the difficult decisions made in the cities in Europe and the USA and Canada, the scale and rate of growth are unprecedented. The McKinsey Report (2009, p. 77) presents an interesting comparison between the urbanization process in China and the USA in terms of the scale (population growth), speed (time in stages of development), and income (per capita GDP), as shown in Table 4.

Table 4: Comparison of growth and development phases in China and the USA.

\begin{tabular}{cccc}
\hline $\begin{array}{c}\text { Figures are all indica- } \\
\text { tive estimates and the } \\
\text { development phases } \\
\text { are overlapping }\end{array}$ & Industrialization & $\begin{array}{c}\text { Service- } \\
\text { based } \\
\text { economy }\end{array}$ & $\begin{array}{c}\text { Knowledge- and } \\
\text { information- } \\
\text { based economy }\end{array}$ \\
\hline China Population & $1-2$ million & $2-15$ million & $>15$ million \\
Time & 40 years & 15 years & 10 years \\
Per capita & $<\$ 2000$ & $\$ 2,000-$ & $>\$ 6,000$ \\
GDP & $100,000-$ & $200,000-$ & $500,000-$ \\
Population & 200,000 & 500,000 & 8 million \\
& 200 years & 75 years & 50 years \\
Time & $<\$ 20,000$ & $\$ 20,000-$ & $>\$ 40,000$ \\
Per capita & 40,000 & \\
GDP & & & \\
\hline Based on McKinsey $(2009$, p. 77 , Exhibit 3.2). &
\end{tabular}

In each of the three stages, China's urban population is about 10 times that of the USA (Factor 10), but the reverse is true on the per capita GDP measure, for which USA incomes are 10 times those in China (Factor 10). The most dramatic differences relate to the time over which economies have moved across the three overlapping stages of development, with China typically moving at 5 times the speed that the USA has (Factor $5)$.

It is difficult to operate an effective regulatory framework, as major decisions must be made quickly and there need to be 
strong supporting institutions for effective implementation. It is not possible to promote only one urban structure for sustainable development in China, as there is no single solution, but rather, a range of possibilities. Compactness can reduce the need to commute long distances, and when combined with the local distribution of services and facilities, it enables shorter trips and trip chaining. The densities used in Chinese cities are much higher than those in the west, as 80 dwellings per hectare is considered low density and suitable for a compact urban development on the urban fringe (Zhao et al. 2010). This level is twice that used in London. Polycentric development can also reduce commuting distance, as the colocation of work places and housing allows overall commuting costs to be optimized (Levinson and Kumar 1997), but such flexibility may be less readily available for many in China, where the "market" for housing is still embryonic. The colocation argument has been strong in the USA (Gordon et al. 1989), but even here, recent evidence suggests that commuting times are among the highest in the world, with the current average about 48 minutes per day (The Economist, 30 April 2011, p. 41).

In terms of city planning, urban development in China is completely new territory, as there is no real history on which to base our thinking. In other megacities the growth has taken place over a much longer period of time (Tokyo-Osaka) or is of a lower order of magnitude (Seoul metropolitan region).

Three types of urban structures seem to be emerging (Figure 2$)^{3}$ :

Radial Cities - where there is one city that acts as a strong center, and development is concentrated along the main routes into that center- the classic monocentric city structure (Table

3 Note that the listings are based on the 11 urban networks of cities identified by McKinsey (2009, p. 14), and it has been extended to include further examples.
5). The Chinese variant means that not all employment is concentrated in the city center, but because of the scale of development there are employment centers along each of the radial routes, so distances are reduced as work is closer to where the people live. There may also be green spaces or wedges between the radials, with new town developments at the urban periphery. In China, most of these cities are isolated and are located inland.

City Clusters-where a series of centers emerge in a region of high growth potential, and this develops as a polycentric urban form with substantial network and agglomeration economies. The Chinese variant in this polycentric structure means that employment is distributed across all the major centers so that they have a high degree of jobs-housing balance, but with their own specializations. It also requires a high-capacity rail and road system that allows efficient travel between the main cities in the cluster. This is the largest grouping of cities and places the megacities together in megacity regions, where several major centers are in close proximity to each other. In China these are all on or near to the coast.

In the Pearl River Delta, nine large cities will coalesce to become one megacity region with about 30 million people (Table 6). There are plans for huge infrastructure investment ( $£ 190$ Billion 2011-2017), including 3100 miles of rail, so that it will take a maximum of one hour to move between any of the major centers. Its position adjacent to Hong Kong (7.0 million) will also strengthen its international potential, as it can capitalize on the financial and knowledge-based expertise there. As part of the vision for this megacity region, the transport system will be public-transport-based, with new housing being built only where accessibility to these transport services can be guaranteed. The land-use planning and zon-

Table 5: Key characteristics of the six Chinese radial cities.

\begin{tabular}{|c|c|c|c|}
\hline Radial cities & Urban area population & Metropolitan area population & Average commute time by car \\
\hline Wuhan & $5.15 \mathrm{~m}$ & $8.36 \mathrm{~m}$ & 31 mins \\
\hline Xian & $5.62 \mathrm{~m}$ & $7.82 \mathrm{~m}$ & 29 mins \\
\hline Zhengzhou & $2.85 \mathrm{~m}$ & $7.31 \mathrm{~m}$ & $29 \operatorname{mins}$ \\
\hline Changsha & $2.41 \mathrm{~m}$ & $6.52 \mathrm{~m}$ & 27 mins \\
\hline Kunming & $2.50 \mathrm{~m}$ & $5.34 \mathrm{~m}$ & 29 mins \\
\hline Lanzhou & $2.10 \mathrm{~m}$ & $3.24 \mathrm{~m}$ & 25 mins \\
\hline & \multicolumn{3}{|c|}{$\begin{array}{l}\text { Comment: Potential for future axial growth between Wuhan and } \\
\text { Changsha }(380 \mathrm{~km}) \text { and from Zhengzhou to Jinan }(430 \mathrm{~km}) \text { and } \\
\text { Shijiazhuang }(440 \mathrm{~km}) \text {, both facilitated by new high-speed rail links }\end{array}$} \\
\hline
\end{tabular}


ing systems will be implemented flexibly, mixing high-rise with open space, but there will also be urban extensions to "fill" the spaces between the main cities. This structure seems to have the potential as a flexible form of deconcentrated concentration, breaking away from the historic radial transport networks that arise from monocentric cities and moving development toward polycentric urban forms. The other two city clusters are in the Yangze River Delta and the "triangle" of cities including Beijing, Tangshan, and Tianjin.

Axial Cities - where there are two main city nodes about $300-400 \mathrm{~km}$ apart that provide the end points to a corridor for development, often along high-speed rail and road links. The Chinese variant is more complex, as there are many types of movements within each of the two main cities as well as movements between them. These cities are mainly in the coastal region (Table 7).

Even though this combination of three distinct urban forms presents one means by which urban growth can be accommodated, urban densities (for example, in Shanghai) will still be about four times those in (large) European cities (London, Paris, and Berlin) and other cities (New York and Jakarta), and twice as dense as Moscow. The scale of city size in China is such that it is almost impossible to categorize cities as any particular type, as they are all polycentric even though there are identifiable differences. The distinctions between cities may also disappear as new cities are built and as cities coalesce.

Within these rapidly growing megacities the issues of con- gestion, pollution, and greater accessibility of the denser city need to be matched against the longer distances encouraged by sprawl. The average speed of car travel in central Beijing $(10 \mathrm{~km} / \mathrm{hr})$ and Shanghai $(18 \mathrm{~km} / \mathrm{hr})$ are much lower than those in Singapore $(35 \mathrm{~km} / \mathrm{hr})$ and London $(29 \mathrm{~km} / \mathrm{hr})$, even though the levels of motorization are much lower (McKinsey 2009 , p. 139). This is partly because there is less road space available as a proportion of land space (17 percent in Shanghai as compared with 25 percent in London), but it is also due to lower levels of urban space management, demand management, and enforcement. Even sprawl leads to congestion, as people need to take their cars to the city center, so there is really no choice.

The transport system within cities must be based on rail, BRT, buses, and paratransit for the longer distances, and on bicycle (electric) and walking for the shorter distances. Lowspeed electric vehicles could provide both public and private transport as well as delivery and other services in the city. The importance of urban planning is paramount in reducing the demand for long-distance commuting by establishing local centers for work and housing in compact developments across the megacities. In all cases, it is important to consider the balance of development in central areas and in the urban fringe, so that proximity and accessibility (preferably by walking and cycling or public transport) can be promoted. This means shifting the emphasis from providing additional road infrastructure to one that considers sustainable communities within the poly-

Table 6: Key characteristics of the three Chinese city clusters.

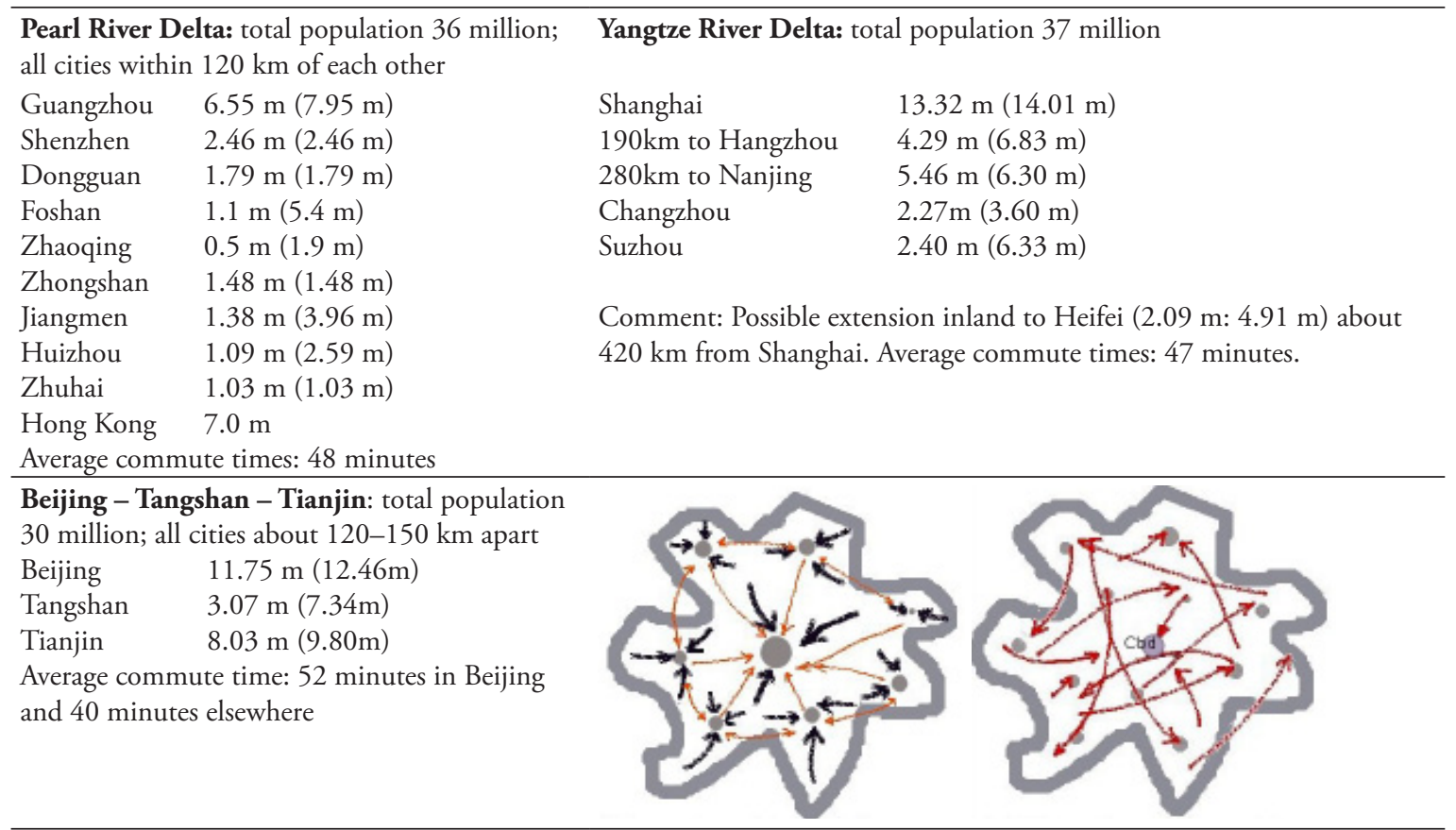

Notes: Population figures (2009) from the China Bureau of Statistics (2010) for the urban area and for the metropolitan areas in brackets; commute time data from a Deloitte Survey (2011). 
Table 7: Key characteristics of the four Chinese axial cities.

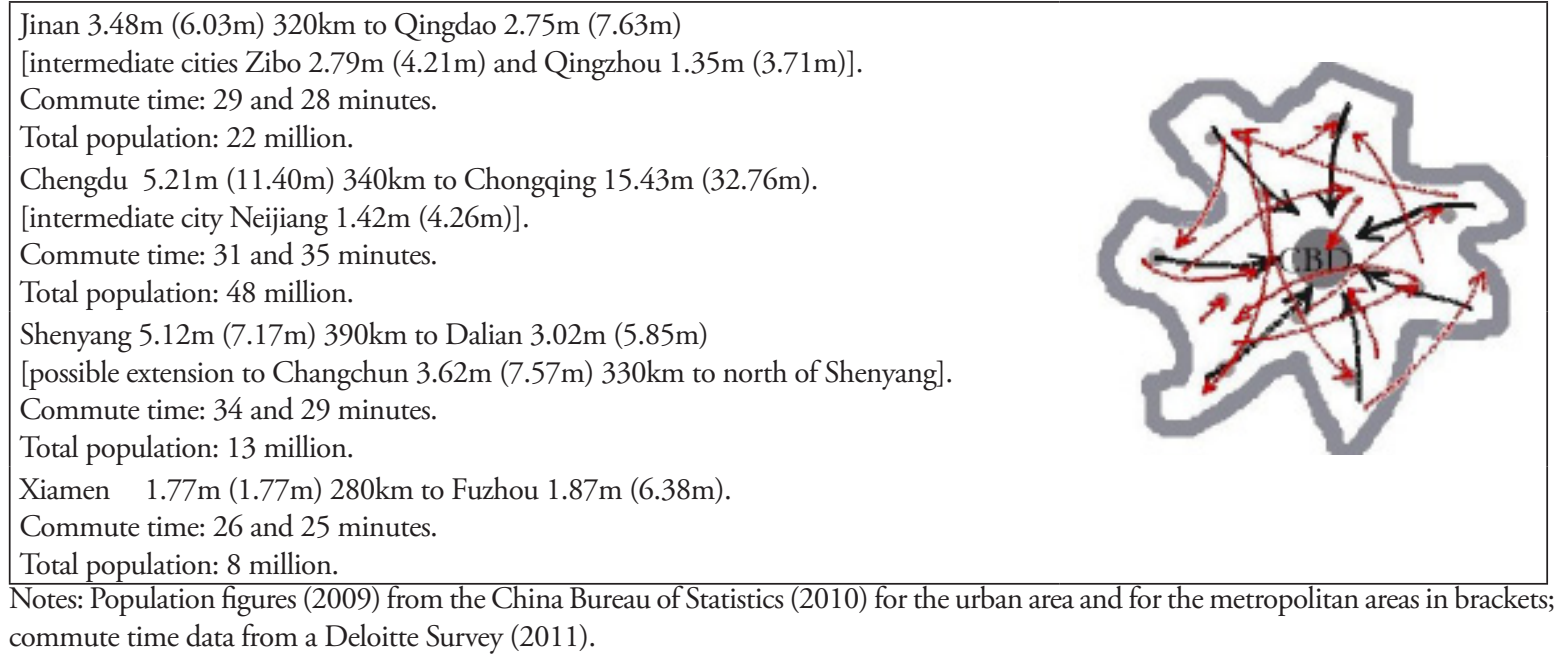

centric megacity regional structure. Large-scale transport projects and technical innovations are key elements in supporting city development, and in some situations they might even lead that development, but they do not necessarily solve the problems of carbon, pollution, and congestion.

High-speed rail offers a clear opportunity for high levels of connectivity both within and between cities, as there is no doubt that the demand for travel is justified by the huge urban populations. As noted above, the axial cities need such investment to link the two end points, but even within the clusters there is a strong case for rail links between the component cities. The high-speed rail network provides the means to extend the axial lines and to integrate the cities nationally.

In summary, the urban form of Chinese cities can be shown (Figure 2) using the graphic behind Bertaud's views of city development (2002) and the individual components used

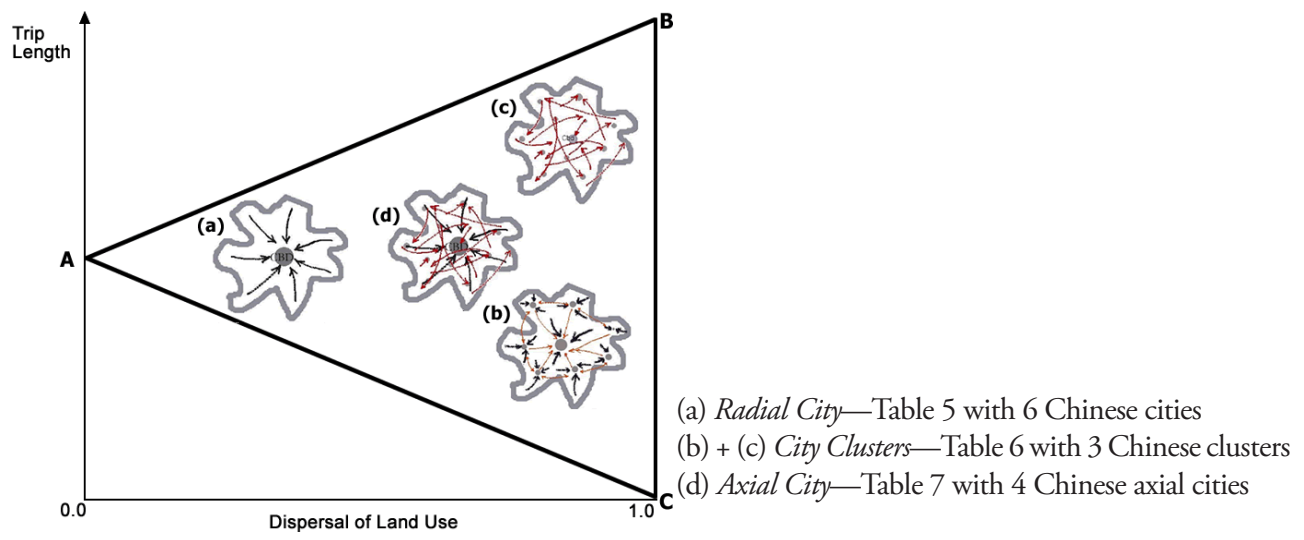

Figure 2: The relationship between trip length, dispersal, and urban form.

Notes: City (a) is the monocentric model with a strong central city and a radial pattern of travel; City (b), the polycentric model, with a cluster of surrounding cities; City (c), the polycentric model, with random movements, and City $(\mathrm{d})$, the multicenterd city with simultaneous radial and random movement, but this can be focused into the axial city with corridors of movement (Bertaud 2002).

(a) Radial City-Table 5 with 6 Chinese cities

(b) + (c) City Clusters - Table 6 with 3 Chinese cluster in Tables 5, 6, and 7. This illustrates the different urban forms and the relationships between trip length and density of land use, and it provides the classic view on the tradeoffs that must be made.

\section{Conclusion}

In many ways, the message of this paper is optimistic, in that many cities in Europe are now sustainable-at least in terms of transport in their everyday activities, as more than 50 percent of trips are made by walking and cycling. Public transport plays an important role for travel over longer distances, and in many cases the role of the car is being questioned. Quality of life and urban living are seen as the main driving forces here, with good-quality, low-carbon mobility facilitating all movement. To some extent, cities in the USA and Canada are 
following the same pathway, but it is more difficult there as distances are much greater. More opportunities are being taken to concentrate development and to build at higher densities through mixed-use and balanced approaches. Technology may also have a key role to play here through greater efficiency in car design. But there is also great potential through new forms of ownership (leasing and car sharing), and through a reduced need to travel resulting from the adoption of new working and social activity patterns. Social and work-based networking offer immense possibilities to again change the nature of physical movement and other forms of communication so that flexibility is maintained within the transport system.

The growth in the megacities present new possibilities and problems, with key questions being raised here as to whether the solutions used elsewhere can be adapted and applied here. Part of the problem relates to the scale and rate of change, but another part to the speed at which the land-use planning system can adapt to the requirements now being placed on it. For example, much of the traditional thinking is to provide a built environment and transport system that will last at least 100 years, and investment decisions are made on that basis, examining all the costs and benefits and discounting them over 30 or 60 years. The new agenda requires that a far quicker decision process and far greater flexibility be included in any major decision, as land values, land uses, and travel patterns are all changing over a much shorter period of time and industrialization moves into service-based and knowledge-based futures.

Glaeser (2011) takes these themes even further in his passionate plea for tall towers to reduce environmental costs and enhanced productivity (height, not sprawl, p. 259). He reflects on the last century as the time when transport costs were low, which eliminated the production advantages of the industrial city, and people moved to the suburbs and to the car-based cities of the US Sunbelt. But now the advent of new technologies has increased the returns for new ideas, and this in turn has revitalized the rationale for the city as the only place for faceto-face collaboration.

\section{References}

Banister, D. 2005. Unsustainable Transport: City Transport in the New Century, London: Routledge

Banister, D. 2007. 'Cities, Urban Form and Sprawl: A European Perspective', ECMT Round Table 137, pp. 113-142 and paper presented at the OECD/ECMT Regional Conference Workshop, Berkeley, CA, March 2006.

Bertaud, A. 2002. Note on transportation and urban spatial structure. Paper presented at the ABCDE Conference,
Washington, DC, April.

Breheny, M. (ed.) 1992. The Compact City - Special Issue of Built Environment 184: 659-674.

Breheny, M. and Archer, S. 1998. Urban densities, local policies and sustainable development, International Journal of Environment and Pollution 101: 126-150.

Buchanan, C. 1963. Traffic in Towns, London: HMSO.

Calthorpe, P. 1993. The Next American Metropolis - Ecology, Community and the American Dream, New York: Princeton Architectural Press.

CEC Commission of the European Communities. 1992. Sustainable Mobility: Impact of Transport on the Environment, COM 9246., Brussels: CEC.

Cervero, R. 2008. Effects of TOD on Housing, Parking and Travel, Transit Cooperative Research Program Report 128, Washington, DC: Federal Transit Administration.

Chen, C., Gong, H. and Paaswell, B. 2008. Role of the built environment on mode choice decisions: Additional evidence on the impact of density, Transportation 354: 285299.

China National Bureau of Statistics. 2010. China City Statistical Yearbook, Beijing: National Bureau of Statistics.

Deloitte Global Services Limited. 2011. Gaining Traction Will consumers ride the electric vehicle wave? Electric vehicle consumer survey resulst for China, US, Europe and Japan.

Department of the Environment, Transport and the Regions. 1998. The Use of Density in Urban Planning, Report for the Planning Research Programme by the Bartlett School of Planning and Llewelyn Davies Planning, London: The Stationery Office.

Duany, A., Plater-Zyberk, E. and Speck, J. 1992. Suburban Nation: The Rise of Sprawl and the Decline of the American Dream. New York, NY: North Point Press.

European Commission. 2010. EUROPE 2020: A Strategy for Smart, Sustainable and Inclusive Growth. Brussels: European Commission.

Ewing, R., Bartholomew, K., Winkelman, S., Walters, J., Chen, D., McCann, B. and Goldberg, D. 2007. Growing Cooler: The Evidence on Urban Development and Climate Change, , Washington, DC: Urban Land Institute and Renewable Resources Journal 25(4): 6-13.

Ewing, R. 1997. 'Is Los Angeles style sprawl desirable?', Journal of the American Planning Association, 63(1): 107-126.

Ewing, R. and Cervero, R. 2002. 'Travel and the Built Environment - Synthesis', Transportation Research Record 1780, TRB, Washington.

Ewing, R. and Cervero, R. 2010. Travel and the built environment, Journal of the American Planning Association 76(3): 
265-294.

Geddes, P. 1915. Cities in Evolution: An Introduction to the Town Planning Movement and to the Study of Civics, London: Williams.

Givoni, M. and Banister, D. 2010. Integrated Transport: From Policy to Practice, London: Routledge.

Glaeser, E. 2011. Triumph of the City, London: Macmillan.

Gordon, P., Kumar, A. and Richardson, H.W. 1989. Congestion, changing metropolitan structure and city size in the United States, International Regional Science Review 12(1): 45-56.

Grant, J. 2006. Planning the Good Community: New Urbanism in Theory and Practice, London and New York: Routledge.

Hall, P. 1988. Cities of Tomorrow, Oxford: Blackwell.

Hall, P. 2001. Sustainable cities or town cramming? In Planning for a Sustainable Future, London: Spon, pp. 101-114.

Hall, P. and Tewdwr Jones, M. 2010. Urban and Regional Planning, 5th Edition. London: Routledge.

Handy, S. 2004. 'Accessibility v Mobility-enhancing Strategies for Addressing Automobile Dependence in the US', Paper presented at the ECMT round table on Transport and spatial Policies: The Role of Regulatory and Fiscal Incentives, RT124, Paris, November 2002, pp. 49-85.

Haughton, G. and Hunter, C. 1994. Sustainable Cities, London: Jessica Kingsley Publishers.

Hickman, R. 2007. 'Reducing Travel by Design: A Micro Analysis of New Household Location and the Commute to Work in Surrey', Unpublished PhD Thesis, Bartlett School of Planning, University College London, London

Holtzclaw, J. 1994. Using Residential Patterns and Transit to Decrease Auto Dependence and Costs, Washington, DC: National Resources Defense Council.

Howard, E. 1902. Garden Cities of Tomorrow, London: S. Sonnenschein and Co., Ltd.

Ingersoll, R. 2006. Sprawltown, New York: Princeton.

Jacobs, J. 1961. The Death and Life of the Great American Cities, New York: Random House.

Krizek, K.J. 2003. 'Residential relocation and changes in urban travel: does neighbourhood scale urban form matter', Journal of the American Planning Association, 69(3): 265-281.

Krugman, P. 1991. Increasing returns in economic geography, Journal of Political Economy 99: 483-499.

Krugman, P. 2011. The new economic geography, now middle aged, Regional Studies 45(1): 1-7.

Levinson, D. 2008. Density and dispersion: The co-development of land use and rail in London, Journal of Economic Geography 8(1): 55-77.

Levinson, D. and Kumar, A. 1997. Density and the journey to work, Growth and Change 28: 147-172.
Litman, T.A. 2007. Land use impacts on transport: How land use factors affect travel behaviour, Victoria Transport Policy Institute.

McKinsey Global Institute. 2009. Preparing for China’s Urban Billion. http://www.mckinsey.com/mgi/publications/ china_urban_billion/

Meadows, D.H., Meadows, D.L., Randers, J. and Behrens III, W.W. 1972. The Limits to Growth, New York: Universe Books.

Mumford, L. 1938. The Culture of Cities, London: M. Secker and Warburg

Neuman, M. 2005. The compact city fallacy, Journal of Planning Education and Research 25(1): 11-26.

Norman, J., MacLean, H.L. and Kennedy, C.A. 2006. Comparing high and low residential density: Life-cycle analysis of energy use and greenhouse gas emissions, Journal of Urban Planning and Development, 132(1): 10-21.

Rogers, R. and Burdett, R. 2001. Lets cram more into the city, in Cities for the New Millennium, London: Spon, pp. 9-14.

Schäfer, A., Heywood, J.B., Jacoby, H.D. and Waittz, I.A. 2009. Transportation in a Climate Constrained World, Cambridge, Mass.: MIT Press.

Stokes, G. 2011. Poverty and travel behaviour in Great Britain - what the National Travel Survey tells us. TSU Working Paper Series, 1053, School of Geography and the Environment, Oxford.

Storper, M. 2011. From retro to avant-garde: A commentary on Paul Krugman's The new economic geography, now middle aged, Regional Studies 45(1): 9-15.

Tripp, A. 1942. Town Planning and Traffic, London: Edward Arnold.

UN Habitat. 2009. Planning Sustainable Cities, Global Report on Human Settlements, London: Earthscan.

Wachs, M. 2002. Transportation demand management: The American experience. Why what works is unpopular and what is popular doesn't work, Sustainable Transport in Sustainable Cities- Why Travel? The Warren Centre for Advanced Engineering, The University of Sydney.

Zhao, P., Lu, B. and de Roo, G. 2010. Urban expansion and transportation: The impact of urban form on commuting patterns on the city fringe of Beijing, Environment and Planning A 42: 2467-2486. 